\title{
Research on the Human-animal God Images of Shanhai Ching Shuyan $\mathrm{Yi}^{1, \mathrm{a}}$ \\ ${ }^{1}$ College of Humanities \&Sciences of Northeast Normal University, Chang chun, Ji lin, China, 130117 \\ ayishuyan2013@126.com,
}

\section{Keywords: Shanhai Ching; Human-animal; God Image; Mythology.}

\begin{abstract}
Shanhai Ching is an important ancient book of the pre-Qin Period, where the God images not only provide important literature material for researchers to understand the early religious thought, but also provide intuitive picture evidence. The human-animal is the second stage of the development of the God image, as compared with the whole beast God image that belongs to the more advanced god image created by the Chinese ancients and reflected the humane tendency of God. Based on the relevant text analysis, it can be found that the human-animal god image has the characters of both the man and the animals, which is mainly the combination of different parts of the body of man and beasts, and the number of which in Shanhai Ching is rich. This god images are originated from different animals, such as the snake, the dragon, the bird and the fish, etc. This is the embodiment of the primitive totem worship psychology, which reflects the rising status of human. The primitive people had different feelings towards different animals. After all, through the related God image's text content in Shanhai Ching, researchers not only can have deep contact with the image of God, but also can find the development track of the Chinese mythology. It is thus very important to study the origin of mythology.
\end{abstract}

\section{Introduction}

As an important ancient book of pre-Qin period, Shanhai Ching has recorded the mythology. It is not only considered as the earliest but also the most abundant ancient book, which is handed down from the ancient times to present in China. Not only the God's number of which is rich, but also the God's image is bizarre. Therefore, they have great research value. Through the classification of different God images of Shanhai Ching, it can reveal the deep ideological and cultural connotations hidden behind, which has great advantage to grasp the ancient human spirit worship psychological development[1][2][3].

The human-animal god image is the second phase of development of God image. The combinations have the characters of both the man and the animal, which is mainly the combination of different parts of the body of man and beasts.[4] In accordance with the "beast" of different types, the human-animal combination is mainly divided into four types: the human-snake combinations god image, the human-dragon combinations god image, the human-bird combinations god image, the human-fish combinations god image. Different images reflect different significance, the details are as follows.

\section{Analysis of the Human-snake God Image}

The character of the human-snake god image is that the god's body is mainly made of human's head and snake's body. This god image has a high frequency of occurrence in Shanhai Ching. According to statistics, only in Beishan Ching, this human-snake god image appears for 42 times. The whole beast God is the God completely composed by the combination of animal organs. The examples and analysis are as follows.

The totem is the snake's body with a human's head.[5](Beishan Ching) 
The Candle Dragon, which totem is the red snake's body with a human's body, his eyes are long straight and his full-length is more than 500 kilometers. When he closes his eyes, the world is dark; when he opens his eyes, the world is bright. He does not eat, never sleep and never breath. (Dahuangbei Ching)

Xiang Liu has the totem of the navy snake's body and nine human's body. (Overseas bei Ching)

The human-snake god image reflects the worship of the primitive. Comparing with the Scripture of Shanhai Ching, researchers can find that most snakes have the magic ability, they will lead to the emergence of drought disasters when appear. Such as:

In Hunxi Mountain, there is no tree or grass, but copper and jade. It is where the Xiao River originates and the river flows northwest into the sea. Here lives a snake, Feiyi. It not only has one head but also two bodies. Its appearance forecasts a big drought. (Beishan Ching)

In Yunyumufeng Mountain, there lives a big snake, which is white all over but with a red head. It cries like cattle. Its appearance forecasts a drought. (Beishan Ching)

Based on the above two verses, the snake act as a villain. When appears, it can bring negative effects for a long time without rain. Meanwhile, in Shanhai Ching, the snake also has a magical effect as it also appear with water. Take Xiangliu for example, the scripture is described as "Where he rest and activity, it is water", and "There are a lot of water in his presence, not to live". As researchers have seen above, Xiangliu had an inseparable relationship with water.

According to two positive and negative examples above, researchers can summarize that in the ancient times, snake is snake and water is inextricably linked. Through the ancient archaeological data, researchers can found the ancient's worship of the snake.[6] In the Dawenkou Period of late matriarchal society, Serpentine pattern has emerged in ceramics, as shown in Fig. 1. This shows that the worship of the snake has existed for a very long history.

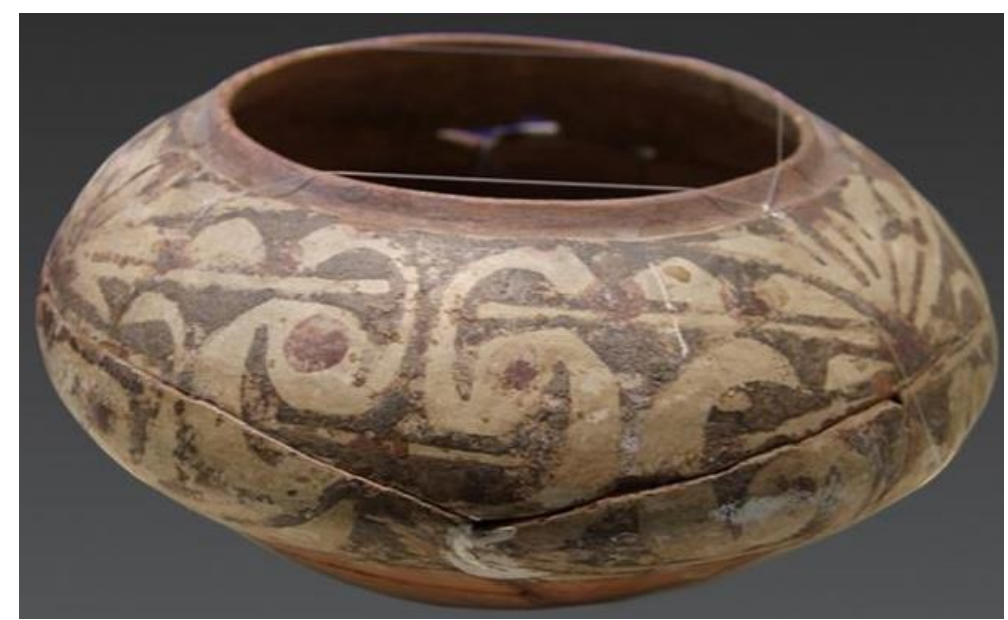

Fig. 1 The Ceramic Utensils Unearthed in Dawenkou Site

The reason why the ancients believed that there was correspondence between the snake and water was the reliance of ancient agricultural developmen on the weather. To the ancients, no rain for a long time was one of the most terrible natural disasters, which would lead to the failed crop, and then directly affected the ancient village life. From its appearance or survival characteristics, the snake was closely linked with water. Thus the ancients began to worship the snake, and the snake was added to their own god image. They worshiped the jade, rooster, pig, rice and other offerings to God, in order to express their pious heart, obtain God forbid, and get good living conditions. 


\section{Analysis of the Human-dragon God Image}

The character of the human-dragon god image is that the god's body is mainly made of human's part and dragon's part. This god image frequently occurs in Shanhai Ching. The examples and analysis are as follows.

The totem is a dragon's body with human's face. The etiquette of sacrifices: the animal sacrifice is to offer a dog. And grain is the rice. (The Third Part of Nanshan Ching)

$\mathrm{Gu}$ is the mountain spirit of Zhong Mountain; it has a dragon's body with a man-like face. (The Second Part of Xishan Ching)

The totem is a human's body with a dragon's face. (The First Part of Dongshan Ching)

Guang mountain top produces jasper with much water underneath. Here is the territory of Jimeng absolute being and it usually plays in the Zhangyuan. When it comes out or into the water, it blows a strong wind, and it rains heavily. (The Eighth Part of Zhongshan Ching)

Combined with the different body parts of the dragon and the people, the ancients created the above different god images. This reflects the primitive worship of the dragon. The reason why the ancients worship the dragon is that the dragon has a direct correspondence with water. The later documents have many records on this, such as "The cloud from the dragon, the wind from the tiger" coming from Yijing and the custom "Pray for rain Dragon" coming from the Dong Zhongshu's "Chunqiu Fanlu" in the Western Han Dynasty. Therefore, the ancients have generated the worship to dragon.

\section{Analysis of the Human-bird God Image}

The character of the human-bird god image is that the god's body is mainly made of human's part and bird's part. To the bird, its body, head, wing and beak are often chosen. To human, his face, hand and body are often chosen.[7] The examples and analysis are as follows.

In the East Overseas, there is a god named Jumang, he has a bird's body with a man-like face, and rides two dragons. (Haiwaidong Ching)

In the North Overseas, there is a god named Yuqiang, he has a bird's body with a man-like face. His ears hang two snakes and his feet steps two snakes. (Haiwaibei Ching)

In Beijitianju Mountain, there lives a god named Nine Phoenix, he has a bird's body with nine man-like faces. (Dahuangbei Ching)

The Huaijiang Mountain is the Emperor's back garden, there are a lot of gold and silver mountains, and the god Yingzhao manages the mountain. He has a horse's body with a man-like face, also has tiger body patterns and bird's wings. (The Third Part of Xishan Ching)

By comparing with these different images of the above gods, researchers found that the bird wings are their common characteristics. Therefore, in order to have the ability to free-flying like the birds, the original settlers created these gods.

At the same time, "Shanhai Ching" also describes some devastating human-bird god images. When they appear, they often bring disaster, war, or even subjugation and other ill omens. Such as:

In the Lingqiu Mountain, there lives a king of bird caller Yu, resembling owl but with the face like a human being; it has four eyes and ears. When this animal appears, a big drought happens. (The Third Part of Nanshan Ching)

In the Yanzi Mountain, there lives a bird. It has the shape of an owl but a human's face. Its body is like monkey and it has a dos's tail. If it appears, a big drought is to happen right away. (The Fourth Part of Xishan Ching)

For the scriptures, when these birds appear, they will bring very serious consequences and have a direct impact on the survival of mankind. At this point, people worship the birds out of fear and psychological feelings.

In short, the ancients have very complex feelings to the birds, including the feeling of envy, fear and worship. This shows that the ancients pay much attention to the bird. The birds mainly have the flying ability, so their greatest wish is to have a pair of wings like bird. In this psychological 
effect, the human-bird god image was created. Because the ancients believe that when they have the bird's organs, they will have the corresponding ability of the bird, which can enhance their ability to conquer nature. In the Liangzhu Culture 5300-4200 years ago, most of the unearthed jades have bird images, which provides the direct evidence for bird worship.

\section{Analysis of the Human-fish God Image}

The character of the human-fish combinations god image is that the god's body is mainly made of human's part and fish's part. Compared with the above three human-beast god images, it has a relatively small number. Such as:

Diren Country is in the west of Jianmu, its people have the image of human's head with a fish's body and no foot. (Haiwainan Ching)

The Lingfish is the image of human's face, human's hand and foot and a fish's body who lives in the sea. (Haiwaibei Ching)

According to the above different images, researchers found that these gods' bodies are made of both human's organs and fish's organs, and they have some magical abilities of fish. This not only shows the ancients' wild imaginations, but also embodies their worship of fish.

From Scripture records, it can be found that the main reasons for the ancients' worship of fish are shown as follows:

In the ancient times, the natural disasters occurred very frequently, people are susceptible to various skin diseases, and even lose their life. Through long-term observation, they found that the fish's body is very smooth, and then thought fish have the ability to treat skin disease.

Fish can be food. One of American ethnologists Morgan studied that "Fish is one of the early human food, they are distributed everywhere and unlimited supply, which are the only food people can get at any time." [8]

The fish has the ability to swim freely in water. The ancients hope to have this ability, in order to avoid the flood disaster.

In the Banpo Culture 4000 years ago, the worship of fish had already existed.[9] The "Human face fish basin" is the direct evidence for the worship of fish, as shown in Fig. 2.

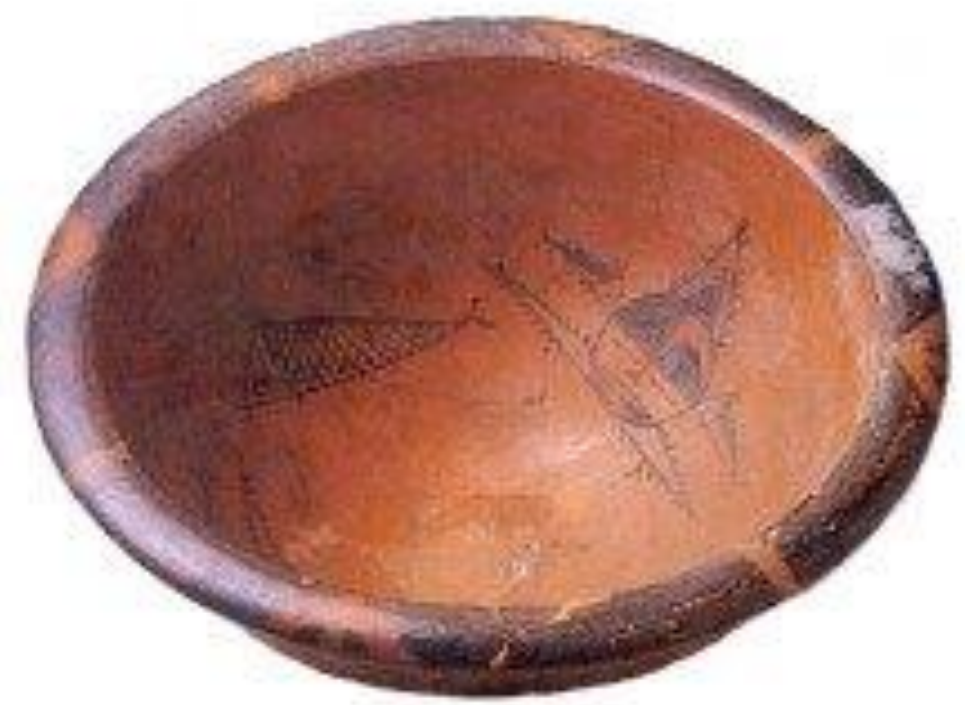

Fig. 2 The Human Face Fish Basin Unearthed in Banpo Culture Site 


\section{Conclusion}

As Mao Dun said, "The so-called 'myth', which is the accumulation of knowledge of the ancients, includes their cosmology, religious thought, ethics, original legend of national history and the understanding of nature.[10] Unlike the whole-beast God image, the human-animal god images have human organs. This showed that the ancients have come out from the absolute worship of the surroundings, and no longer use the simple pleasing ways to seek comfort. They had increasingly great confidence, and slowly learned to solve their own problems. However, due to the incomplete confidence in their own ability, they still needed many powerful creatures that they worshiped earlier for comfort. Thus, the ancients envy the special abilities of animals, and then graft these special abilities of animals to themselves through the myth. This produces human-animal god images. As a result, they are a product of the Chinese ancient "heaven" views of nature.[11] By using this way, the ancients hope to realize the harmony between man and nature.

\section{Acknowledgment}

This paper is one of the initial results of the Jilin Province Department of Education Project, the fund name is "Research on the Mythology of Guopu's Shanhai Ching Note", and which number is 2014B056.

\section{References}

[1] [Jin] P. Guo, Notes Shanhai Ching (Photocopy this Complete Library in Four Branches of Literature), Shanghai Ancient Books Publishing House, Chinese, 1999.

[2] Y.S. Fu, Ancient Ritual Culture, Higher Education Press, Chinese 2005, pp. 88.

[3] K. Yuan, Shanhai Ching School Note, Shanghai Ancient Books Publishing House, Chinese, 1980, pp. 68.

[4] X.S. Ye, Theoretical Studies in Literature and Art, Vol. 181 (2012) No.2, pp.24.

[5] Z.D. Liu, The Lost bible--Shan Hai Ching and the ancient China world, Commercial Press, Chinese, 2010.

[6] X.H. Liu, Chinese Civilization Yi October Calendar, Yunnan People's Publishing House, Chinese, 1986, pp. 33.

[7] H. Wu, Bird Image IN EGL Art, SDX Joint Publishing Company, Chinese, 2005, pp. 28.

[8] Morgan, The ancient society, The Commercial Press, Chinese, 1983.

[9] S.Y. Yi, Y.S. Fu, Research of Chinese Literature, Vol. 103 (2011) No.4, pp.28.

[10] D. Mao, The meaning and category of myth, Shandong literature and Art Publishing House, Chinese, 1986, pp. 143.

[11] X.X. Dong, Shandong Social Sciences, Vol. 145 (2007) No.9, pp.22. 